Research Paper:

\title{
Comparison of Psychological Hardiness and Resiliency of Employed and Unemployed Female-headed Household
}

\author{
Anahita Khodabakhshi-Koolaee ${ }^{{ }^{*}}$ (iD \\ 1. Department of Psychology and Educational Sciences, Faculty of Humanities, Khatam University, Tehran, Iran.
}

\begin{tabular}{|l|l|l|}
\hline $\begin{array}{l}\text { use your device to scan } \\
\text { and read the article online }\end{array}$ & $\begin{array}{l}\text { Citation: Khodabakhshi-Koolaee, A., 2020. Comparison of Psychological Hardiness and Resiliency of Employed and } \\
\text { Unemployed Female-headed Household. Journal of Client-Centered Nursing Care, 6(1), pp. 7-12. https://doi.org/10.32598/ } \\
\text { JCCNC.6.1.33.7 }\end{array}$ \\
dol' https://doi.org/10.32598/JCCNC.6.1.33.7
\end{tabular}

\section{(c) (1) (8)}

Article info:

Received: 22 Feb 2019

Accepted: 18 May 2019

Published: 01 Feb 2020

Keywords:

Female-headed

households, Hardiness,

Resiliency

\begin{abstract}
A B S T RA C T
Background: Employed and unemployed women have their special problems. This issue could be more important for female-headed households. Hardiness and resiliency are among the characteristics that are critical for fighting against life problems. This study aims to compare the psychological hardiness and resiliency of employed and unemployed female-headed households.

Methods: This research was a comparative cross-sectional study. The sample included 120 female-headed households (60 employed and 60 unemployed) living in Tehran City, Iran from March to June 2018. The subjects were recruited among the women referring to the institutions affiliated with Imam Khomeini Relief Foundation in Tehran, Iran. The data were collected by the psychological hardiness scale and the Connor-Davidson resilience scale and analyzed in SPSS V. 21 using frequency, mean, standard deviation, and multivariate analysis of variance.
\end{abstract}

Results: The results indicated a significant difference between employed and unemployed women in terms of psychological hardiness $(32.03 \pm 11.50$ vs $27.91 \pm 9.24)(\mathrm{P}=0.034)$. Besides, there was a significant difference between these women in terms of resiliency $(64.881 \pm 1.03 \mathrm{vs}$ $59.55 \pm 12.72)(\mathrm{P}=0.016)$.

Conclusion: The results indicated a significant difference between psychological hardiness and resiliency among employed and unemployed subjects. Also, the fundamental plans should be made for female-headed households so that they can remain independent and pursue a job.

\footnotetext{
* Corresponding Author:

Anahita Khodabakhshi-Koolaee, PhD.

Address: Department of Psychology and Educational Sciences, Faculty of Humanities, Khatam University, Tehran, Iran.

Tel: +98 (912) 2343717

E-mail: a.khodabakhshid@khatam.ac.ir
} 


\section{Highlights}

- The female-headed household population is growing all over the world and in Iran as well.

- The majority of female-headed households are single mothers. They are responsible for bringing food to the home and take care of their children.

- It is necessary to design basic programs and make the right decisions to empower the female-headed household. These programs should include finding jobs, health insurance, and training new skills.

\section{Plain Language Summary}

It is estimated that three million female-headed households live in Iran. These women become heads of households for various reasons such as the death of the husband or divorce, immigration, disappearing, fatal accidents or imprisonment, termination of marriage, military service, sickness, disability, addiction, and unemployment. Some psychological traits such as hardiness and resiliency, make people more resistant to life's challenges. This study reveals that the psychological hardiness and resiliency of employed female-headed households is more than their unemployed counterparts.

\section{Introduction}

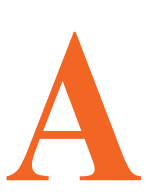

ccording to the World Health Organization, many women are responsible for providing financial support for their family members. The divorce rate has increased by $1.3 \%$ in Iran over the past decade which has resulted in an increase in the female-headed household's population from $8.4 \%$ to $9.4 \%$ during the period between the 2006 censuses to 2016 censuses. The estimated number of female-headed households in Iran is 3 million (Orojloo \& Koolaee 2016). There are a variety of reasons for this condition, including the death of the husband or divorce, immigration, disappearing, fatal accidents, imprisonment, termination of marriage, military service, sickness, disability, addiction, and unemployment. These women are responsible for the care and management of the economy and making the vital decisions of the family (Cheeseman, Ferguson \& Cohen 2011; Orojloo \& Koolaee 2016). They also play different roles at the same time. They take care of children, provide shelter, finance the family, and be a father for children. So they have to bear a lot of responsibilities which results in psycho-emotional stress (Bradshaw, Chant \& Linneker 2017). This vulnerable group is generally under more financial stress than male-headed households, because women earn fewer and lower incomes positions, and usually have fewer assets (Espinoza-Delgado \& Klasen 2018). Furthermore, some social factors such as social attitudes (gender inequality) and government policies suppress these women (Liu, Esteve \& Treviño 2017).
Paying attention to the influential personality factors in the lives of female-headed households is not just a matter of one minority group in society, but it relates to the many pressures of life they experience (Mahmoudvandi-Baher, Flasafinejad \& Khodabakhshi-Koolaee 2018; Najjari, Khodabakhshi-Koolaee \& Falsafinejad 2017). Women under these pressures should have adequate coping resources and personality characteristics.

Among the personality characteristics, psychological hardiness and resiliency have drawn more attention. Psychological hardiness that was introduced by Kobasa and Maddi in 1979 is a set of personality traits that determine the degree of resistance of a person in stressful situations (Bradshaw, Chant \& Linneker 2019). This psychological characteristic consists of three components of commitment (in the sense of being active against problems rather than being passive in front of them), controlling (believing that the events of life are controllable and predictable), and fighting (meaning that life challenges are an opportunity for growth and one can benefit from failure as well as success) (Windle, Bennett \& Noyes 2011; Hu, Zhang \& Wang 2015). Another factor influencing the mental health of the vulnerable segments of society is resiliency. Resiliency refers to the psychological capacity of a person to deal with problems (Seyedoshohadaee et al., 2018). This attribute represents how much a person can show positive behavior in dealing with difficult conditions and mental strokes (Fletcher, \& Sarkar 2013).

Orojloo and Koolaee (2016) reported that female-headed households who have jobs and income have higher re- 
siliency and hope than their jobless counterparts. Moreover, it has been stated that employed female-headed households could better take care of their children and had higher psychological hardiness than unemployed females (Mirzaee Sagherlo \& Koolaee 2020).

Psychological hardiness and resiliency are variables that can affect the psychological state of women who are the head of their households. This study aimed at comparing psychological hardiness and resiliency of employed and unemployed female-headed households in Iran.

\section{Materials and Methods}

This research was a comparative cross-sectional study. The study population consisted of 120 employed and unemployed female-headed households in Tehran City, Iran. The study was done from March 2018 to June 2018. The subjects were recruited by a convenient sampling method from three welfare and charity centers in the South of Tehran, Iran. The centers included Reihana Al-nabi Charity, Al-Hour Charity and welfare complex, and Hamraz Clinic which are affiliated to Imam Khomeini Relief Foundation. The groups of female-headed households were selected from the available list of the centers and were matched by age, education level, and the cause of being the head of the household.

The inclusion criteria were as follows: being the head of the household and employed for the first group, being the head of the household and unemployed for the second group, being 30 to 55 years old, and being able to read and write. The subjects would be excluded if they had mental disorders such as depression and anxiety or were dissatisfied to participate in the study.

The data were collected by Psychological Hardiness Scale (PHS) and the Connor-Davidson Resilience Scale (CDRISC). PHS has 20 questions, including three subscales of commitment (questions 1 to 9), control (questions 10 to 16), and combat (questions 17 to 20). It is a 4-point Likert-type scale and scored from never $=0$ to most times $=3$. Higher scores indicate higher psychological hardiness (Kobasa, Maddi \& Kahn 1982). Kobasa et al. tested the internal consistency of the scale by the Cronbach alpha (0.81) (Maddi $\&$ Kosaba 1994). The reliability of the translated version of the scale was confirmed in our study by test-retest as 0.87 . The CD-RISC consists of 25 items which are scored on a 5-point Likert type scale ranging from $0=$ not true at all, $1=$ rarely true, $2=$ sometimes true, $3=$ often true, and $4=$ true nearly all of the time (Cheeseman, Ferguson \& Cohen 2011). Total ratings range from 0 to 100 , and higher scores indicate higher resilience (Connor \& Davidson 2003).
The internal consistency of the scale was confirmed by the Cronbach alpha as 0.89 (Burns \& Anstey 2010). The reliability of the translated version in our research was established by test-retest as 0.87 .

Before distributing the questionnaires, the participants were given the needed information and explanations, and they were assured that their information would remain confidential. All the questionnaires were completed at the charity centers.

To analyze the data, descriptive statistics such as frequency, mean, and standard deviation were used. To measure the normality of variables, Box's M and Levene's tests were used. Also, to analyze the hypotheses, multiple analysis of variance was used by SPSS V. 21.

\section{Results}

As mentioned before, the subjects were matched by all variables except for employment status (Table 1).

Table 2 provides the means, standard deviations, and $\mathrm{F}$ test results of all the variables used in this study.

According to Table 2, the results of multivariate analysis of variance showed a significant difference between the commitment $(\mathrm{P}=0.023)$, total psychological hardiness $(\mathrm{P}=0.034)$, and resiliency $(\mathrm{P}=0.016)$ between the employed and unemployed female-headed households. There was no significant difference between control $(\mathrm{P}=0.139)$ and combat $(\mathrm{P}=0.194)$ subscales in the groups of women.

\section{Discussion}

The study results showed that the mean scores of psychological hardiness and resiliency of the employed women were higher than those of their unemployed counterparts. These psychological characteristics can be useful in reconciling the individual with the environment and tense events of life. Besides the financing, having a job could lead to a person's psychosocial mobility and satisfies self-esteem and empowerment (Bradshaw, Chant \& Linneker 2019). According to the results, among the subscales of psychological hardiness, only the commitment subscale was significant. Commitment creates a sense of purpose and makes life activities important and meaningful for such a person. Thus, they can respond positively to the stresses of life (Fletcher \& Sarkar 2013). Scholars describe the component of commitment to psychological hardiness as a mental protective against anxiety (Kobasa, Maddi \& Kahn 1982; Maddi \& Kosaba 1994). Women's protection against poverty is very important in developing countries. Alazzawi compared five 
Table 1. Sociodemographic characteristics of the employed and unemployed female-headed households

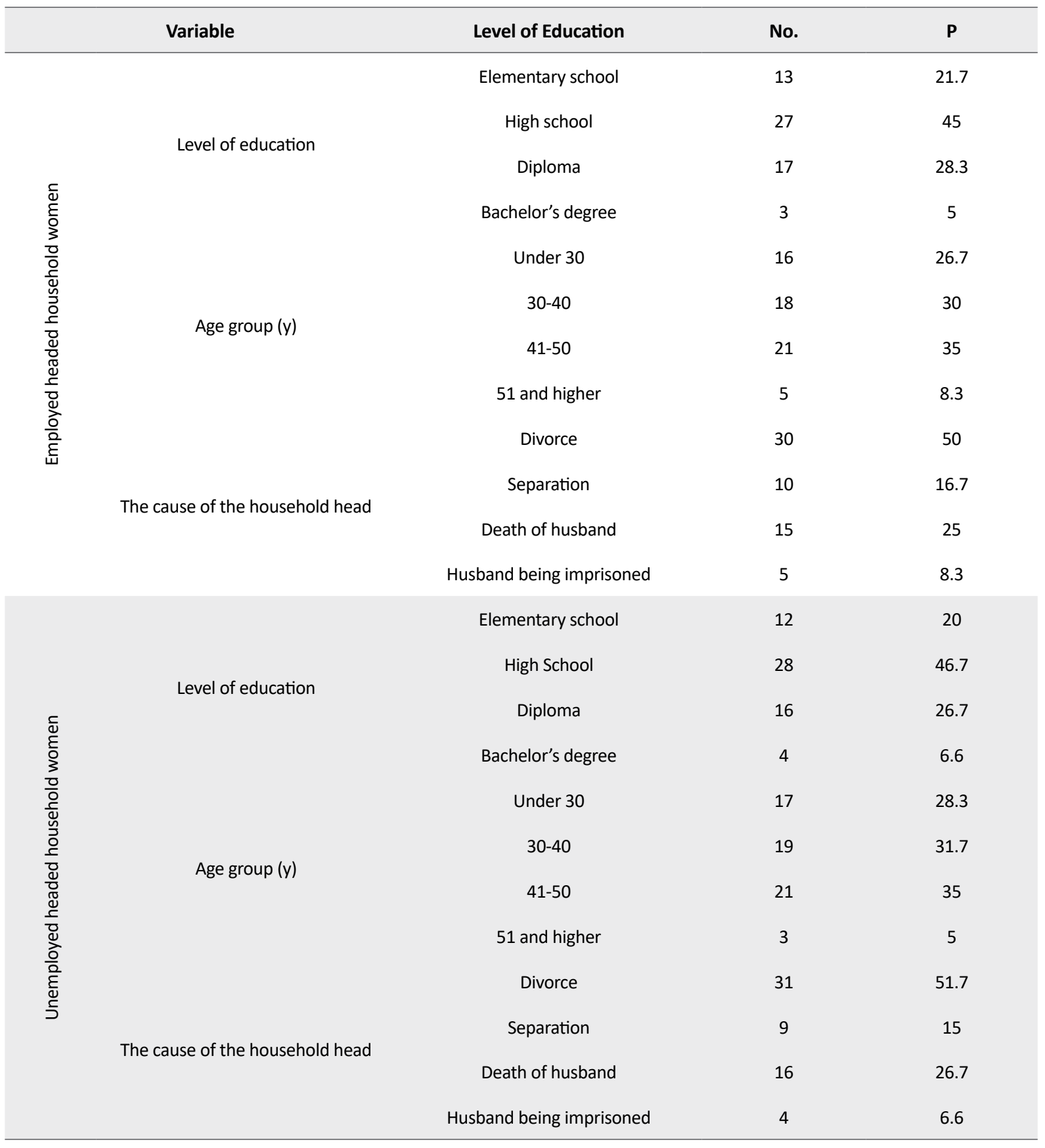

Client- Centered Nursing Care

household types in Egypt and indicated that the femaleheaded households were poorer than other groups, especially in urban areas (Alazani 2018). It is believed that the women who have a job and take responsibility for their life have more psychological hardiness (Orojloo \& Koolaee 2016; Liu, Esteve \& Treviño 2017).

There was a difference between the resiliency of the employed and unemployed female-headed households. This feature in women housewives makes them more adaptable to the miseries of life. Such women are more likely to become self-employed and work in different professions, and that is why this component is more prevalent in working-class women than in jobless ones (Liu, Esteve \& Treviño 2017; Bradshaw, Chant \& Linneker 2019). The employment and economic wellbeing of single femaleheaded households were studied in the United States in the years 2004, 2007, 2010, and 2013. The findings re- 
Table 2. Multivariate analysis of psychological hardiness and its subscales and resiliency of female-headed households

\begin{tabular}{|c|c|c|c|c|c|c|c|}
\hline \multirow{2}{*}{ Variables } & \multirow{2}{*}{ Groups } & \multirow{2}{*}{ Mean $\pm S D$} & \multicolumn{5}{|c|}{ F-test } \\
\hline & & & MS & df & SS & $\mathbf{F}$ & $\mathbf{P}$ \\
\hline \multirow{3}{*}{ Commitment } & 1 & $14.50 \pm 4.24$ & \multirow{3}{*}{143.00} & \multirow{3}{*}{1} & \multirow{3}{*}{143.00} & \multirow{3}{*}{5.28} & \multirow{3}{*}{0.023} \\
\hline & & & & & & & \\
\hline & 2 & $12.50 \pm 6.0$ & & & & & \\
\hline \multirow{3}{*}{ Control } & 1 & $18.80 \pm 4.36$ & \multirow{3}{*}{42.00} & \multirow{3}{*}{1} & \multirow{3}{*}{42.00} & \multirow{3}{*}{2.21} & \multirow{3}{*}{0.135} \\
\hline & & & & & & & \\
\hline & 2 & $19.98 \pm 4.35$ & & & & & \\
\hline \multirow{3}{*}{ Combat } & 1 & $7.28 \pm 3.03$ & \multirow{3}{*}{15.40} & \multirow{3}{*}{1} & \multirow{3}{*}{15.40} & \multirow{3}{*}{1.707} & \multirow{3}{*}{0.19} \\
\hline & & & & & & & \\
\hline & 2 & $6.56 \pm 2.97$ & & & & & \\
\hline \multirow{3}{*}{ Psychological hardiness (total score) } & 1 & $32.03 \pm 11.50$ & \multirow{3}{*}{508.40} & \multirow{3}{*}{1} & \multirow{3}{*}{508.40} & \multirow{3}{*}{4.53} & \multirow{3}{*}{$0.03<$} \\
\hline & & & & & & & \\
\hline & 2 & $27.91 \pm 9.24$ & & & & & \\
\hline \multirow{3}{*}{ Resiliency } & 1 & $64.881 \pm 1.03$ & \multirow{3}{*}{853.33} & \multirow{3}{*}{1} & \multirow{3}{*}{853.33} & \multirow{3}{*}{6.01} & \multirow{3}{*}{0.016} \\
\hline & & & & & & & \\
\hline & 2 & $59.55 \pm 12.72$ & & & & & \\
\hline
\end{tabular}

SD: Standard Deviation; df: Degree of freedom; F: F-test; P<0.05;

1. Employed ; 2. Unemployed.

vealed that employed women have some employer contribution to health but the unemployed women have no other resources than depending on the government for medical benefits. The unemployed female-headed households had higher self-care problems, lower levels of education, and lower reported levels of health status than their employed counterparts. The researchers concluded that unemployed women who were the heads of their households would benefit from suitable jobs (Neethi 2017). Other studies have also shown that in general, the female-headed households with lower income had lower wellbeing, low food security, and low health care (Binti Wan Mustapa, Al Mamun \& Ibrahim 2018; Tibesigwa \& Visser 2015).

Resilient personality is not only a stand against problems but also an active barrier against the outside environment (Burns \& Anstey 2010). The women with such personalities also work better in interpersonal relationships, because they can understand their emotions and others, and as a result, they have a stronger social support network. The job environment creates a suitable opportunity for these women to experience more hardiness and resiliency (Khodabakhshi Koolaee Hosseinian \& Falsafinejad 2014).

The questionnaires in our study were self-reported, so the respondents might answer them carelessly or with doubt. It is suggested that further research be conducted on the female-headed household occupation in Iran. In addition, the relationship of other variables such as age and education can be added to the research process.

According to the results of this study, the psychological hardiness and resiliency are different between the two groups of employed and unemployed female-headed households. In other words, providing job opportunities to enable the women to face hard conditions should be considered by the government and social welfare organization.

\section{Ethical Considerations}

\section{Compliance with ethical guidelines}

The study was approved by the Research Committee of Khatam University (Ethical Code: Kh.96. S.101.2530). The needed information about the study was given to the subjects and all of them signed the informed consent.

\section{Funding}

This research was extracted from the Research Project at Khatam University.

\section{Authors' contributions}

All of elements of article had been done by Dr. Anahita khodabakhshi-koolaee. 


\section{Conflict of interest}

The authors declared no conflict of interest.

\section{Acknowledgments}

The author would like to thank the women participating in this research and the Welfare Organization of Tehran Province.

\section{References}

Alazzawi, S., 2018. Do endowments matter? Exploring the gender dimensions of poverty in Egypt. Review of Income and Wealth, 64(s1), pp. S189-224. [DOI:10.1111/roiw.12390]

Binti Wan Mustapa, W. N., Al Mamun, A. \& Ibrahim, M. D. 2018. The effect of economic vulnerability on the participation in development programs and the socio-economic well-being of low-income households. Societies, 8(3), p. 60. [DOI:10.3390/ soc8030060]

Bradshaw, S., Chant, S. \& Linneker, B., 2017. Gender and poverty: What we know, don't know, and need to know for Agenda 2030. Gender, Place \& Culture, 24(12), pp. 1667-88. [DOI:10.108 0/0966369X.2017.1395821]

Bradshaw, S., Chant, S. \& Linneker, B., 2019. Challenges and changes in gendered poverty: The feminization, de-feminization, and refeminization of poverty in Latin America. Feminist Economics, 25(1), pp. 119-44. [DOI:10.1080/13545701.2018.1529417]

Burns, R. A. \& Anstey, K. J., 2010. The Connor-Davidson Resilience Scale (CD-RISC): Testing the invariance of a uni-dimensional resilience measure that is independent of positive and negative affect. Personality and Individual Differences, 48(5), pp. 527-31. [DOI:10.1016/j.paid.2009.11.026]

Cheeseman, S., Ferguson, C. \& Cohen, L., 2011. The experience of single mothers: Community and other external influences relating to resilience. The Australian Community Psychologist, 23(2) pp. 32-49. https://www.psychology.org.au/APS/media/ $\mathrm{ACP} /$ Cheeseman-et-al-ACP-2-11.pdf

Connor, K. M. \& Davidson, J. R. T., 2003. Development of a new resilience scale: The Connor-Davidson resilience scale (CDRISC). Depression and Anxiety, 18(2), pp. 76-82. [DOI:10.1002/ da.10113] [PMID]

Espinoza-Delgado, J., \& Klasen, S., 2018. Gender and multidimensional poverty in Nicaragua: An individual based approach. World Development, 110, pp. 466-91. [DOI:10.1016/j. worlddev.2018.06.016]

Fletcher, D. \& Sarkar, M., 2013. Psychological resilience: A review and critique of definitions, concepts, and theory. European Psychologist, 18(1), pp. 12-23. [DOI:10.1027/1016-9040/a000124]

Hu, T., Zhang, D. \& Wang, J., 2015. A meta-analysis of the trait resilience and mental health. Personality and Individual Differences, 76, pp. 18-27. [DOI:10.1016/j.paid.2014.11.039]
Khodabakhshi Koolaee, A., Hosseinian, S. \& Falsafinejad, M. R 2014. [Comparing of coping stress strategies and self-concept between married educated women with job and without job (Persian)]. Quarterly Journal of Career \& Organizational Counseling, 6(18), pp. 9-21. http://jcoc.sbu.ac.ir/article/view/3350

Kobasa, S. C., Maddi, S. R., \& Kahn, S., 1982. Hardiness and health: A prospective study. Journal of Personality and Social Psychology, 42(1), pp. 168-77. [DOI:10.1037/0022-3514.42.1.168] [PMID]

Liu, C., Esteve, A. \& Treviño, R., 2017. Female-headed households and living conditions in Latin America. World Development, 90, pp. 311-28. [DOI:10.1016/j.worlddev.2016.10.008]

Maddi, S. R. \& Khoshaba, D. M., 1994. Hardiness and mental health. Journal of Personality Assessment, 63(2), pp. 265-74. [DOI:10.1207/s15327752jpa6302_6] [PMID]

Mahmoudvandi-Baher, E., Flasafinejad, M. R., \& KhodabakhshiKoolaee, A., 2018. [The effectiveness of emotion-focused group therapy on hope and negative automatic thoughts among divorced women (Persian)]. Community Health, 5(1), pp. 67-76. https://www.magiran.com/paper/1825559?lang=en

Najjari, F., KhodabakhshiKoolaee, A. \& Falsafinejad, M. R., 2017. [The effectiveness of group therapy based on Acceptance and Commitment (ACT) on loneliness and psychological adjustment in women after divorce (Persian)]. Journal of Torbat Heydariyeh University of Medical Sciences, 5(3), pp. 68-75. http://jms. thums.ac.ir/article-1-459-en.html

Neethi, D. J., 2017. Employment and economic wellbeing of single female-headed households [MSc. thesis]. New York: Annandaleon-Hudson University. http://digitalcommons.bard.edu/ levy_ms $/ 5$

Orojloo, S. \& Khodabakhshi Koolaee, A., 2016. [Comparison between personality traits and hope among female-headed households with or without tendency towards remarriage (Persian)] Community Health (Salāmat-i ijtimāī), 3(2), pp. 101-10. https:// www.sid.ir/en/Journal/ViewPaper.aspx?ID =601243

Mirzaee Sagherlo P, Khodabakhshi Koolaee A., 2020. [Child custody challenges for divorced mothers: A phenomenological study (Persian)]. Iranian Journal of Pediatric Nursing, 6(3), pp. 5361. http://jpen.ir/article-1-468-fa.html

Seyedoshohadaee, M., et al., 2018. The effect of self-care education on the resilience of the patients with heart failure. Journal of Client-centered Nursing Care, 4(3), pp. 165-72. [DOI:10.32598/ jccnc.4.3.165

Tibesigwa, B. \& Visser, M., 2015. Small-scale subsistence farming food security, climate change and adaptation in South Africa: Male-female headed households and urban-rural nexus. $\mathrm{Eco}^{-}$ nomic Research Southern Africa, (527), pp. 1-32. https://www. datafirst.uct.ac.za/dataportal/index.php/citations/5324

Windle, G., Bennett, K. M., \& Noyes, J., 2011. A methodologica review of resilience measurement scales. Health and Quality of Life Outcomes, 9, p. 8. [DOI:10.1186/1477-7525-9-8] [PMID] [PMCID] 